\title{
Tuberculosis of Oral Mucosa Mimicking Malignancy: A Case Report
}

\author{
Pramod R C ${ }^{1}$, Suresh K V², Sunil L $A^{3}$, Mohan Kumar K $\mathrm{P}^{4}$
}

Senior Professor ${ }^{1}$, Reader ${ }^{4}$, Department of Oral Pathology and Microbiology, College of Dental Sciences, Davangere

Faculty of Dentistry ${ }^{2}$ SEGI university No 9 Jalan Teknologi Taman Sains Selangor, Malyasia'

Senior lecturer ${ }^{3}$, Dept of Public Health Dentistry, College of Dental Sciences, Davangere

\section{Abstract:}

Tuberculosis (TB) is an epidemic infectious disease that seldom takes an oral form. Because of the still increased incidence of TB in our country, in the differential diagnosis of chronic oral ulcerations, tuberculosis should always be considered. Oral TB is frequently overlooked as a possible cause of oral ulceration. Therefore dentists should be aware of the possible occurrence of TB of the oral cavity.

Keywords: Langhans giant cell, mycobacterium tuberculosis, oral tuberculosis

\section{Introduction}

Tuberculosis (TB) is a chronic granulomatous disease and a leading cause of death in developing countries. TB affects mucous membrane of oral cavity and genitalia, could be either primary or secondary to autoinoculation of Mycobacterium tuberculosis from underlying advanced TB infection of lung, genitourinary or gastrointestinal tract respectively. ${ }^{1}$ Tuberculosis has been the most important of human infections in its global prevalence, devastating morbidity and massive mortality. The incidence of tuberculosis in the oral cavity is quite rare. It could be either primary or secondary to pulmonary disease. There are about $1-1.5 \%$ cases of pulmonary tuberculosis with associated oral cavity lesions..$^{2-4}$ The oral sites most frequently affected are the tongue, palate, tonsil, pharynx, and buccal mucosa. The vulnerability to $\mathrm{TB}$ in developing countries results from poverty, economic recession and malnutrition. ${ }^{1}$

Oral lesions have a non-specific presentation varying from ulcers to granulomas, fissures and may be overlooked. Here we report a case of TB of oral mucosa in 35 years old male patient.

\section{Case Report}

A 35 year old male presented with painful ulcerative swelling on right side of the buccal mucosa near mandibular 2 nd and 3rd molar tooth. The patient also had productive cough, weakness, weight loss and

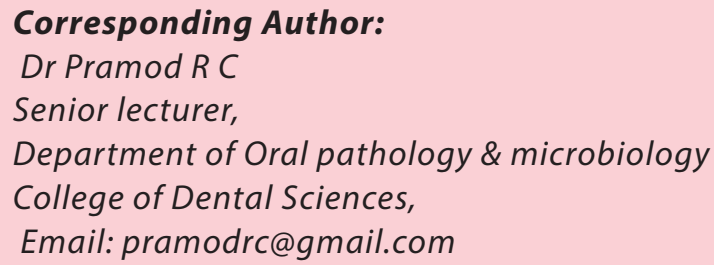

difficulty in opening mouth. Patient had history of pulmonary TB one year back for which he had taken complete anti tuberculosis therapy (ATT) with Isoniazid $600 \mathrm{mg}$, Rifampicin $450 \mathrm{mg}$ and Pyrazinamide 1500mg, Ethambutol 1200mg for two months followed by Rifampicin and Isoniazid for four months. Patient had no history of dental trauma or any oral surgery or tobacco chewing. Oral examination revealed tender, growth of 2 $\mathrm{X} 1.5 \mathrm{~cm}$ with irregular margins, covered with mucopurulent discharge and slough in the right retro molar trigone (Figure. 1).

On palpation growth was indurated and with undermined margins. Cervical lymph nodes were neither enlarged nor fixed to surrounding tissue. Based on clinical findings a diagnosis of squamous cell carcinoma was given. An incisional biopsy was taken from the growth sent for histopathological examination. Routine hematological and biochemical investigations and the chest X-ray did not reveal any abnormality. No radiographic evidence of involvement of underlying bone was seen. Serological tests done for syphilis and HIV were found negative. Histopathological examination with hematoxylin and eosin stain $(\mathrm{H}$ and $\mathrm{E})$ of the one tissue section did not reveal any carcinoma component rather showed multiple granuloms comprises of lymphocytes, Langhans type giant cells and caseous necrosis. (Figure.2)

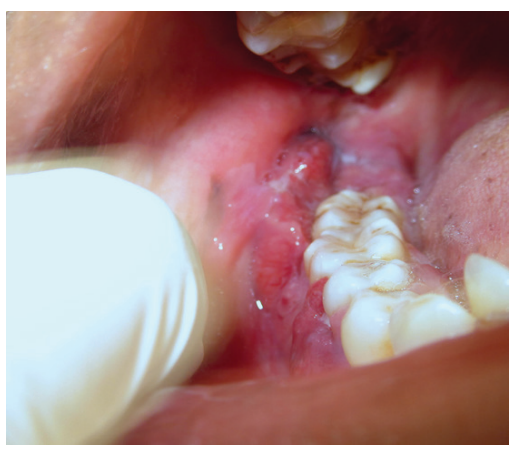

Figure 1: Clinical picture showing growth in the retro molar trigone area 


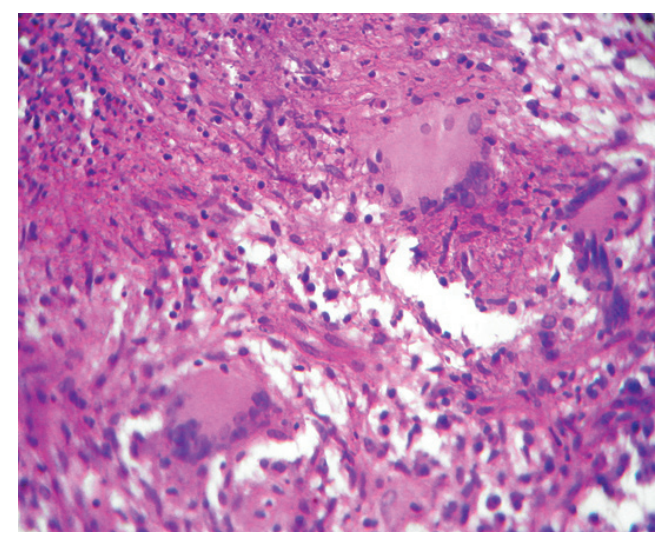

Figure 2: Photomicrograph (40x) showing langhans giant cell with in granuloma

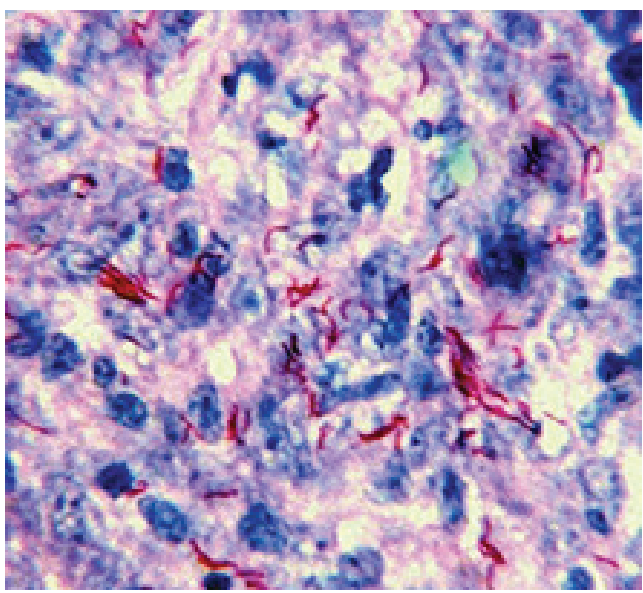

Figure 3: Photomicrograph (100x) showing ZN staining showed presence of acid fast bacilli within granuloma

\section{Discussion}

TB is caused by the bacteria mycobacterium tuberculosis, which is an aerobic, non-motile, non-capsulated, non-spore forming and rod shaped organism ${ }^{1}$. Tuberculous lesions of the oral cavity may be primary or secondary. The primary tuberculosis of the oral cavity is very rare ${ }^{5}$. In primary oral tuberculosis the organisms are directly inoculated on the oral mucosa of a person who has not been previously infected. The role of trauma is controversial, as the stratified squamous epithelium of the oral cavity normally resists direct penetration by tubercle bacilli. In the secondary type, oral tuberculosis usually coexists with pulmonary disease. Self-inoculation may take place from infected sputum or hematogenous seeding ${ }^{2-5}$.

Primary oral TB is observed more commonly in children and adolescents. It usually involves the gingiva, mucobuccal folds or extraction sites, and is often associated with enlarged cervical lymph nodes ${ }^{6}$. Secondary oral TB usually coexists with pulmonary disease, may occur in all age groups; however, middle-aged and older people are more likely involved. The most frequently occurring lesion is a painful ulcer, characterized by irregular edges with minimal induration ${ }^{7}$. The base of an ulcer may be granular or covered with a pseudo membrane. The dorsal surface of the tongue is affected most commonly 3 followed by the palate, buccal mucosa and lips. The salivary glands, tonsils and uvula are also involved frequently ${ }^{5}$.

The oral lesions may present in a variety of forms, such as ulcers, nodules, tubercular fissure, tubercular papilloma, tuberculomas and peri-apical granulomas. The typical presentation is that of a single indurated painful ulcer with irregular borders covered by inflammatory exudates, but atypical cases with multiple lesions or asymptomatic ulcers have also been described ${ }^{1}$.

However, M. tuberculosis cannot invade the intact mucosa of oral cavity. The squamous epithelium is resistant to invasion to tubercle penetration. This has been attributed to the cleansing action of saliva; the presence of salivary enzymes, tissue antibodies, and oral saprophytes; and the thickness of the protective epithelial covering. Any break or loss of this natural barrier, which may be the result of trauma, chronic irritation or inflammation, leukoplakia, tooth extraction, or poor oral hygiene, may provide a route of entry for the organism $^{6}$. The ulcer is usually formed by breakdown of tubercles and usually has an undermined edge. Many times presentation may mimic malignancy as being nodular and ulcers not typical of tuberculosis. Tubercular ulcers are usually more irregular than punched out lesions of carcinoma. In our case, ulcer had rolled margins with induration mimicking squamous cell carcinoma of buccal mucosa ${ }^{7}$.

The differential diagnosis of a tubercular ulcer of the oral cavity includes aphthous ulcers, traumatic ulcers, syphilitic ulcers and malignancy, including primary squamous cell carcinoma, lymphoma and metastases. As reported here, the most likely clinical diagnosis is that of a squamous cell carcinoma, in which case biopsy is mandatory. It is most likely that tuberculosis is only considered when the histological specimen reveals a granulomatous lesion. Other mimics of granulomatous inflammatory conditions in oral cavity are sarcoid, Crohn's disease, the deep mycoses, cat-scratch disease, foreign-body reactions, tertiary syphilis and Melkersson-Rosenthal syndrome ${ }^{8}$. 
The diagnosis of tuberculosis is confirmed by histopathological examination, presence of acid-fast bacilli in tissue section, or by culture of tubercular bacilli. In majority of the cases, a single biopsy may not suffice because the granulomatous changes may not be evident in early lesions. The lesion is eventually disclosed by a repeat biopsy ${ }^{9}$ as was observed in our case. However biopsy taken from superficial site or inappropriate site may be negative for granulomatous changes.

\section{Conclusion}

Tuberculous lesions of the oral cavity may mimic squamous cell carcinoma more than other oral pathologies. When diagnosing oral ulcerations with non healing tendency, the dental and oral surgeons should actively pursue tuberculosis in the differential diagnosis. By avoiding the overlook of the tuberculous etiology of oral ulcers, the oral surgeons can early detect tuberculosis and prevent further contamination.

\section{References}

1. Eng HL, Lu SY, Yang CH, Chen WJ. Oral tuberculosis. Oral Surg Oral Med Oral Pathol Oral Radiol Endod.1996; 81:415-420.

2. Anantnarayan R, Jayaram Paniker C K. Textbook of Microbiology, 8th edition, 2009, Universities Press (India) Private Limited.
3. Hathiram BT, Grewal DS, Irani DK, Tankwal PM, Patankar M. Tuberculoma of the cheek: a case report. J Laryngol Otol. 1997; 111:872-873.

4. Chakraborty AK. Epidemiology of tuberculosis; Current status in India. Indian J Med Res. 2004; 120:248-76

5. Sharma AB, Laishram DK, Sarma B. Primary tuberculosis of tongue. Ind J Pathol Microbiol. 2008; $51: 656$.

6. Rinaggio J. Tuberculosis. Dent Clin North Am. 2003; 47:449-65.

7. Khatri BK, Jhalla GS. Tuberculosis of tongue: a case report. Indian J Tuberc. 1971; 18:58-9.

8. Aguiar MC, Arrais MJ, Mato MJ, deArauja VC. Tubrculosis of the oral cavity: a case report. Quintessence Int.1997; 28:745-747

9. Kakisi OK, Kechagia AS, Kakisis IK, Rafailidis PI, Falagas ME. Tuberculosis of the oral cavity: a systematic review. Eur J Oral Sci. 2010; 118:103-109.

\section{How to cite this article:}

Pramod R C, Suresh K V, Sunil L A, Mohan Kumar K P. Tuberculosis of Oral Mucosa Mimicking

Malignancy: A Case Report. CODS J Dent 2015;7: 87-89

Source of support: Nil. Conflict of interest: None Declared. 